Check for updates

Cite this: Phys. Chem. Chem. Phys., 2020, 22, 18294

Received 1st June 2020

Accepted 6th August 2020

DOI: $10.1039 / \mathrm{d} 0 \mathrm{cp} 02953 \mathrm{j}$

rsc.li/pccp

\title{
Laser-assisted synthesis of gold-graphene oxide nanocomposites: effect of pulse duration $\dagger$
}

\author{
Julian A. Bobb, $\mathbb{D} \neq$ Collin J. Rodrigues, $\ddagger$ M. Samy El-Shall $\mathbb{D} *$ and \\ Katharine Moore Tibbetts (D)*
}

\begin{abstract}
Laser photoreduction of metal ions onto graphene oxide (GO) is a facile, environmentally friendly method to produce functional metal-GO nanocomposites for a variety of applications. This work compares $\mathrm{Au}-\mathrm{GO}$ nanocomposites prepared by photoreduction of $\left[\mathrm{AuCl}_{4}\right]^{-}$in aqueous $\mathrm{GO}$ solution using laser pulses of nanosecond (ns) and femtosecond ( $f s$ ) duration. The presence of GO significantly accelerates the $\left[\mathrm{AuCl}_{4}\right]^{-}$photoreduction rate, with a more pronounced effect using ns laser pulses. This difference is rationalized in terms of the stronger interaction of the $532 \mathrm{~nm}$ laser wavelength and long pulse duration with the GO. Both the ns and fs lasers produce significant yields of sub-4 nm Au nanoparticles attached to $\mathrm{GO}$, albeit with different size distributions: a broad $5.8 \pm 1.9 \mathrm{~nm}$ distribution for the ns laser and two distinct distributions of $3.5 \pm 0.8$ and $10.1 \pm 1.4 \mathrm{~nm}$ for the fs laser. Despite these differences, both Au-GO nanocomposites had the same high catalytic activity towards $p$-nitrophenol reduction as compared to unsupported $4-5 \mathrm{~nm}$ Au nanoparticles. These results point to the key role of GO photoexcitation in catalyzing metal ion reduction and indicate that both $\mathrm{ns}$ and fs lasers are suitable for producing functional metal-GO nanocomposites.
\end{abstract}

\section{Introduction}

The unique properties of both metal nanoparticles (NPs) and graphene-based materials such as graphene oxide (GO) and reduced graphene oxide (rGO) have prompted extensive research into the synthesis of metal-GO/rGO nanocomposites. ${ }^{1-3} \mathrm{GO}$ and rGO provide ideal supports for metal NPs due to their high surface area, thermal and chemical stability, and plentiful oxygen functional group defect sites, which facilitate attachment of metal NPs to produce functional materials. ${ }^{1-3}$ In particular, functional nanocomposites consisting of $\mathrm{Au}$ NPs supported on GO and rGO are used for biomedical sensing,, ${ }^{3,4}$ photothermal cancer treatment, ${ }^{3,5}$ heterogeneous catalysis, ${ }^{6,7}$ and plasmonenhanced optoelectronic applications including photocatalysis, photodetectors, and solar cells. ${ }^{8}$

Many synthesis routes to produce metal-GO/rGO materials involve chemical reducing agents and surfactants, ${ }^{7,9-14}$ which are often toxic and environmentally unsustainable. To avoid the use of toxic chemicals, green synthesis approaches to metal-GO nanocomposites using atmospheric plasma, ${ }^{15,16}$ gamma radiation, ${ }^{17,18} \mathrm{UV}$ irradiation, ${ }^{19-22}$ and lasers ${ }^{23-42}$ have been

Department of Chemistry, Virginia Commonwealth University, Richmond,

VA 23284, USA. E-mail: mselshal@vcu.edu, kmtibbetts@vcu.edu;

Tel: +1-804-828-2753, +1-804-828-7515

$\dagger$ Electronic supplementary information (ESI) available: Additional TEM images; quantification of $\mathrm{H}_{2} \mathrm{O}_{2}$ yield. See DOI: $10.1039 /$ d0cp02953j

\$ These authors contributed equally to this work. developed. Laser synthesis of metal-GO nanocomposites typically involves pre-fabrication of GO via the Hummers and Offerman $^{43}$ or related methods, followed by ablation of a solid metal target ${ }^{23-34}$ or photoreduction of metal salts ${ }^{35-42}$ in GO solution. In addition to anchoring metal NPs onto GO in a single step, laser processing typically results in reduction of the oxygen functional groups on the GO to produce rGO or partially reduced GO (prGO). ${ }^{26-28,33-37,39-42,44,45}$

While the facile "top-down" method of ablating solid metal targets to produce NPs is widespread, ${ }^{46}$ this method can present difficulties in controlling metal NP sizes. In particular, nanocomposites consisting of Au NPs and GO synthesized through topdown ablation have often reported broad Au NP size distributions in the range of $10-50 \mathrm{~nm},{ }^{25-27}$ and even studies reporting sub-10 nm Au NPs show polydisperse size distributions with tails extending to $\sim 15-20 \mathrm{~nm}^{24,28}$ In contrast, "bottom up" photoreduction of Au salt precursors can produce exclusively sub-10 $\mathrm{nm} \mathrm{Au} \mathrm{NPs} \mathrm{when} \mathrm{the} \mathrm{processing} \mathrm{time} \mathrm{is} \mathrm{limited.}{ }^{35,38}$

Metal-GO nanocomposites have been synthesized via bottom-up photoreduction using lasers with both nanosecond $\left(10^{-9} \mathrm{~s}, \mathrm{~ns}\right)^{35-38}$ and femtosecond $\left(10^{-15} \mathrm{~s}, \mathrm{fs}\right)^{39-42}$ pulse duration. Because laser excitation of GO is known to induce metal ion reduction, ${ }^{22,35}$ it is unclear whether the laser pulse duration or wavelength should affect properties of metal-GO nanocomposites including the metal NP sizes and degree of GO reduction. In the absence of $\mathrm{GO}$, we recently reported that photoreduction of $\left[\mathrm{AuCl}_{4}\right]^{-}$with $532 \mathrm{~nm}, 8 \mathrm{~ns}$ or $800 \mathrm{~nm}, 30$ fs pulses in water under otherwise 
similar conditions (average laser power, beam diameter) produce different $\mathrm{Au}$ NP size distributions. ${ }^{47}$ These results are attributed to the distinct reduction mechanisms induced by the two lasers. Photoreduction with fs lasers is driven by reactive species such as hydrated electrons formed by water photolysis. ${ }^{4-50}$ In contrast, ns laser pulses induce thermal decomposition of the $\left[\mathrm{AuCl}_{4}\right]^{-}$precursor and photothermal autocatalytic reduction in the presence of AuNPs due to the $532 \mathrm{~nm}$ laser wavelength being resonant with the surface plasmon resonance of $\mathrm{Au}{ }^{47}$ In this work, we report on the role of GO in determining Au NP size distributions, prGO chemical composition, and catalytic activity of $\mathrm{Au}$-prGO nanocomposites produced using ns and fs lasers. Despite the greater acceleration of $\left[\mathrm{AuCl}_{4}\right]^{-}$reduction using the ns laser in the presence of GO resulting and the distinct Au NP size distributions using ns and fs laser processing, the Au-prGO nanocomposites possess similar catalytic activity.

\section{Experimental methods}

\subsection{Materials}

Potassium tetrachloroaurate(III) (Strem Chemicals), HPLC-grade water (Fisher Scientific), and potassium hydroxide (Fisher Scientific) were used as obtained.

Graphene oxide (GO) was prepared according to the Hummers and Offerman method, ${ }^{43}$ by oxidizing high purity graphite powder (99.9999\%, 200 mesh, Alfa Aesar). The resulting yellowish-brown cake was then repeatedly washed with hot deionized (DI) water, and dried under vacuum overnight at $70{ }^{\circ} \mathrm{C}$. A homogeneous yellow dispersion was then obtained by taking the dried $2 \mathrm{mg}$ of GO and sonicating it in $10 \mathrm{~mL}$ of DI water.

From stock solutions of $\mathrm{KAuCl}(25 \mathrm{mM}), \mathrm{KOH}(500 \mathrm{mM})$, and $\mathrm{GO}\left(2 \mathrm{mg} \mathrm{mL}{ }^{-1}\right)$, working solutions containing $0.1 \mathrm{mM} \mathrm{KAuCl}$, $0.35 \mathrm{mM} \mathrm{KOH}$, and $\mathrm{GO}\left(0.0033 \mathrm{mg} \mathrm{mL}^{-1}\right.$ to $\left.0.33 \mathrm{mg} \mathrm{mL}^{-1}\right)$ were prepared. $0.33 \mathrm{mg} \mathrm{mL}^{-1}$ diluted GO solution was also prepared from GO stock solution. The working solutions were prepared 24 hours in advance and stored at $6{ }^{\circ} \mathrm{C}$. Prior to laser processing, working solutions were bought to room temperature and $3 \mathrm{~mL}$ was transferred to a $10 \times 10 \times 40 \mathrm{~mm}$ quartz cuvette.

Quantification of $\mathrm{H}_{2} \mathrm{O}_{2}$ produced during laser processing was performed using the titanium sulfate assay, ${ }^{51}$ as described in detail in our previous work. ${ }^{48,50}$ Briefly, deionized water and $0.33 \mathrm{mg} \mathrm{mL}^{-1}$ GO solution were processed with the fs laser for $240 \mathrm{~s}$ and then filtered to remove solid products. Following filtration, $400 \mu \mathrm{L}$ of titanium(Iv) sulfate $(25 \mathrm{mM})$ was added to the cuvettes and the absorbance of pertitanic acid at $407 \mathrm{~nm}$ quantified.

\subsection{Instrumentation}

The laser systems and experimental setups for ns and fs laser processing have been described in detail in our previous work. ${ }^{47}$ Briefly, the Nd:YAG ns laser system (Lab 170-30, Spectra Physics; $532 \mathrm{~nm}, 8 \mathrm{~ns}, 30 \mathrm{~Hz}$ repetition rate) was set to a pulse energy of $100 \mathrm{~mJ}$. The titanium-sapphire chirped-pulse fs amplifier (Astrella, Coherent, Inc.; $800 \mathrm{~nm}, 30 \mathrm{fs}, 1 \mathrm{kHz}$ repetition rate) was set to deliver $3 \mathrm{~mJ}$ pulses. The average power of both lasers was $3 \mathrm{~W}$. Both laser beams were down-collimated to diameters of $7.0 \mathrm{~mm}$ and $5.5 \mathrm{~mm}$ for the $\mathrm{ns}$ and fs lasers, respectively, before interaction with the precursor solutions. The calculated fluences $\left(F_{0}\right)$ peak powers $\left(P_{0}\right)$ and intensities $\left(I_{0}\right)$ excluding nonlinear effects were $F_{0}=0.24 \mathrm{~J} \mathrm{~cm}^{-2}, P_{0}=12.5 \mathrm{MW}$, $I_{0}=3 \times 10^{7} \mathrm{~W} \mathrm{~cm}^{-2}$ for the ns laser and $F_{0}=0.012 \mathrm{~J} \mathrm{~cm}^{-2}$, $P_{0}=100 \mathrm{GW}, I_{0}=4 \times 10^{11} \mathrm{~W} \mathrm{~cm}^{-2}$ for the fs laser. The significantly lower fluence for the fs laser was due to the lower attainable pulse energy; generating a similar fluence to the ns laser would have required substantially tighter focusing conditions than used for the ns laser, which would have prevented direct comparison of the two lasers. Under the chosen conditions, both $P_{0}$ values exceed the self-focusing threshold in water, ${ }^{52,53}$ so self-focusing and filamentation are expected to increase the actual intensities by a factor of 10 or more. The resulting effective intensities are well below the threshold for optical breakdown in water. ${ }^{54}$

Solutions of $\mathrm{KAuCl}_{4}$ and $\mathrm{GO}$ were subject to laser processing for sufficient time for complete conversion of $\left[\mathrm{AuCl}_{4}\right]^{-}$to AuNPs. Processing time ranged from 240 to $900 \mathrm{~s}$ with the fs laser and from 30 to $420 \mathrm{~s}$ with the ns laser, depending on the GO concentration. For the fs laser experiments, conversion of $\left[\mathrm{AuCl}_{4}\right]^{-}$to AuNPs was determined using a home-built UV-vis spectrometer ${ }^{48}$ to monitor the growth of the surface plasmon resonance (SPR) peak of AuNPs around $520 \mathrm{~nm}$. In the presence of high quantities of GO, conversion of $\left[\mathrm{AuCl}_{4}\right]^{-}$to AuNPs using ns laser processing was too fast to resolve in the home-built instrument, so solutions were irradiated for 5, 10, 15, and $30 \mathrm{~s}$ and characterized in a commercial UV-vis spectrophotometer (Agilent 8453).

\subsection{Characterization}

Transmission electron microscopy (TEM). The Au-prGO nanocomposites were visualized using TEM (JEOL JEM-1230 TEM). A small volume of the processed solution was dropcasted onto a carbon-coated grid (Ted Pella, Inc.) and left to dry for at least 24 hours. Size distributions of the Au NPs were measured using Image J software from different areas of the TEM grid.

Fourier transform infrared spectroscopy (FTIR). FTIR measurements were obtained using the Thermo Scientific, NICOLET iS50 FT-IR instrument. The Diamond Attenuated Total Reflectance (DATR) attachment was used along with the KBR beamsplitter and the DTGS detector.

Raman spectroscopy. Raman spectra were obtained using the Thermo Scientific DXR SmartRaman instrument at $532 \mathrm{~nm}$ and $10 \mathrm{~mW}$. An aperture slit of $25 \mu \mathrm{m}$ was used along with a 180 degree accessory.

X-ray diffraction (XRD). A PANalytical MPD X'/Pert Pro diffractometer with voltage $45 \mathrm{kV}$ and current $40 \mathrm{~mA}$ was used to measure the $\mathrm{X}$-ray diffraction patterns at room temperature using Ni-filtered $\mathrm{Cu} \mathrm{K} \alpha_{1}$ radiation.

X-ray photoelectron spectroscopy (XPS). Spectra were obtained using the ThermoFisher Scientific ESCALAB 250 with a microfocused monochromatic AlK $\alpha$ X-ray source (15 kV) and a doublefocusing full $180^{\circ}$ spherical sector electron analyzer. 


\subsection{Catalytic reduction of $\boldsymbol{p}$-nitrophenol}

The Au-prGO nanocomposites were tested for their catalytic activity towards $p$-nitrophenol (PNP) reduction to $p$-aminophenol (PAP). Freshly prepared solutions of sodium borohydride (50 $\mathrm{mM}$ ) were used for each reaction. PNP stock solution $(1.5 \mathrm{mM})$, stored at $6{ }^{\circ} \mathrm{C}$, was equilibrated to room temperature prior to use. Working solutions of PNP $(0.1 \mathrm{mM})$ and $\mathrm{NaBH}_{4}$ $(10 \mathrm{mM})$ were prepared in $10 \times 10 \times 40 \mathrm{~mm}$ cuvettes. $500 \mu \mathrm{L}$ of $\mathrm{Au}$-prGO solution was added to initiate the PNP reduction. The reaction progress was monitored via in situ UV-vis spectroscopy by the decay of the $p$-nitrophenolate absorbance peak at $400 \mathrm{~nm}$. Reaction completion was determined by the $400 \mathrm{~nm}$ peak ceasing to decay and remaining static for $30 \mathrm{~s}$.

\section{Results}

\subsection{Effect of $\mathrm{GO}$ on $\left[\mathrm{AuCl}_{4}\right]^{-}$reduction}

Fig. 1 displays the UV-Vis spectra taken during laser processing of $0.1 \mathrm{mM}\left[\mathrm{AuCl}_{4}\right]^{-}$with $0.33 \mathrm{mg} \mathrm{mL}^{-1} \mathrm{GO}$ at different times with the ns (a) and fs (b) lasers. The spectra show the emergence of the characteristic Au NP SPR feature around $520 \mathrm{~nm}^{35,40}$ with increased laser processing time. Complete conversion to AuNPs was established when the SPR band growth stopped, which required $15 \mathrm{~s}$ of processing using the ns laser and $240 \mathrm{~s}$ using the fs laser. For comparison, complete reduction of the same quantity of $\left[\mathrm{AuCl}_{4}\right]^{-}$in the absence of GO required $500 \mathrm{~s}$ using the ns laser and $900 \mathrm{~s}$ using the fs laser under the same laser processing conditions. ${ }^{47}$ This significant acceleration of $\left[\mathrm{AuCl}_{4}\right]^{-}$ reduction rate in the presence of GO is consistent with previous reports of the photocatalytic activity of GO for accelerating metal ion reduction..$^{22,35}$ It is notable that GO decreases the required processing time by more than $95 \%$ using the ns laser and only by $68 \%$ for the fs laser, which suggests that GO plays a more significant role in $\left[\mathrm{AuCl}_{4}\right]^{-}$reduction using the ns laser. The origin of this difference will be discussed further in Section 4 .

\subsection{Characterization of Au-prGO nanocomposites}

To assess the effect of GO on the size distributions of Au NPs present in the Au-prGO nanocomposites, TEM analysis was performed on samples prepared with $0.0033 \mathrm{mg} \mathrm{mL} \mathrm{mL}^{-1}$ and $0.33 \mathrm{mg} \mathrm{mL}^{-1} \mathrm{GO}$ using both $\mathrm{ns}$ and fs laser processing. Representative images and the measured size distributions for
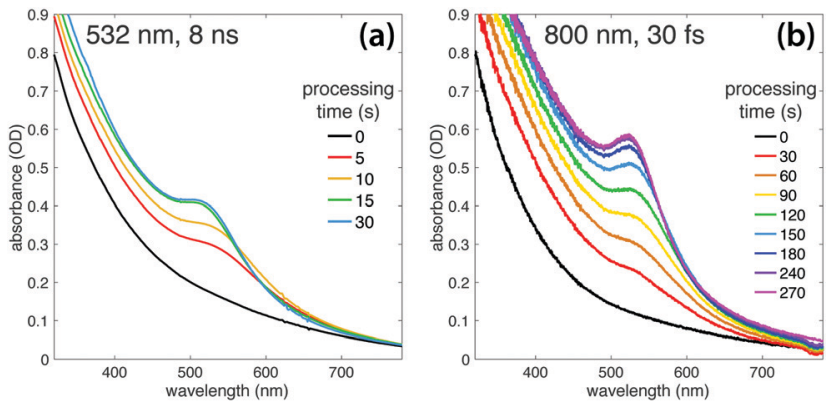

Fig. 1 UV-vis spectra of $\left[\mathrm{AuCl}_{4}\right]^{-} \mathrm{GO}$ solution taken at varying processing times using (a) ns and (b) fs lasers. these four samples are shown in Fig. 2. The size distribution of $5.6 \pm 1.1 \mathrm{~nm}$ obtained with the ns laser and $0.0033 \mathrm{mg} \mathrm{mL}$ GO (Fig. 2(a)) is similar to the $5.1 \pm 1.1 \mathrm{~nm}$ previously reported for the same laser conditions with no added GO. ${ }^{47}$ Increasing the GO concentration to $0.33 \mathrm{mg} \mathrm{mL}^{-1}$ broadens the size distribution to $5.8 \pm 1.9 \mathrm{~nm}$ (Fig. 2(b)). The fraction of sub-4 nm
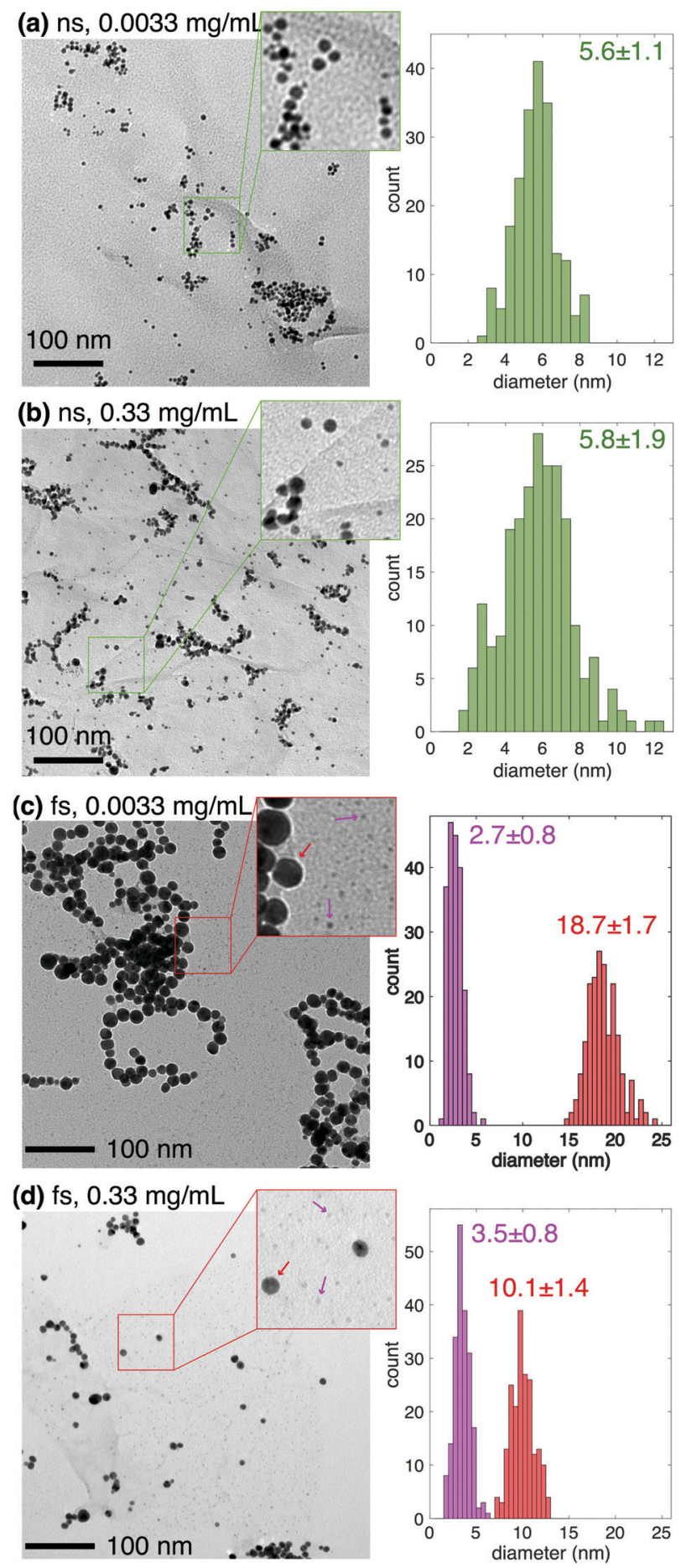

Fig. 2 TEM images and size distributions for (a) ns laser, $0.0033 \mathrm{mg} \mathrm{mL}^{-1}$ $\mathrm{GO}$; (b) ns laser, $0.33 \mathrm{mg} \mathrm{mL}^{-1} \mathrm{GO}$; (c) fs laser, $0.0033 \mathrm{mg} \mathrm{mL}^{-1} \mathrm{GO}$; (d) fs laser, $0.33 \mathrm{mg} \mathrm{mL}^{-1} \mathrm{GO}$. 
$\mathrm{Au}$ NPs more than doubles from $7 \%$ with $0.0033 \mathrm{mg} \mathrm{mL}^{-1} \mathrm{GO}$ to $16 \%$ with $0.33 \mathrm{mg} \mathrm{mL}^{-1} \mathrm{GO}$. A more dramatic change in $\mathrm{Au}$ NP size distributions with increased GO concentration is observed using the fs laser. For $0.0033 \mathrm{mg} \mathrm{mL}^{-1}$, the majority of the Au NPs are large $(18.7 \pm 1.7 \mathrm{~nm}$, Fig. 2(c)), but more monodisperse than the $18 \pm 8 \mathrm{~nm}$ distribution previously reported in the absence of GO under the same conditions. ${ }^{47}$ In some areas there is a separate population of ultrasmall $2.7 \pm 0.8 \mathrm{~nm}$ clusters, indicated by the magenta arrows in the inset of Fig. 2(c). When the GO concentration is increased to $0.33 \mathrm{mg} \mathrm{mL}^{-1}$, the size distribution of the large NPs decreases to $10.1 \pm 1.4 \mathrm{~nm}$ (Fig. 2(d)). The ultrasmall clusters become more numerous relative to the fewer large particles present, and exhibit a modest size increase to $3.5 \pm 0.8 \mathrm{~nm}$. Additional TEM images can be found in the ESI, $\dagger$ Fig. S1 and S2.

FTIR spectroscopy was used to elucidate the nature of the carbon species present after laser processing with ns and fs lasers of $\mathrm{GO}$ alone and in the presence of $\left[\mathrm{AuCl}_{4}\right]^{-}$. The spectrum for unprocessed GO (Fig. 3, black) shows a strong band at $1620 \mathrm{~cm}^{-1}$ corresponding to aromatic $\mathrm{C}=\mathrm{C}$ stretch, along with bands for $\mathrm{C}=\mathrm{O}$ stretch of $\mathrm{COOH}$ groups at $1720 \mathrm{~cm}^{-1}$, O-H deformations of $\mathrm{C}-\mathrm{OH}$ groups at $1360 \mathrm{~cm}^{-1}$, $\mathrm{C}-\mathrm{O}$ stretch of epoxide groups at $1220 \mathrm{~cm}^{-1}$, and $\mathrm{C}-\mathrm{O}$ stretching

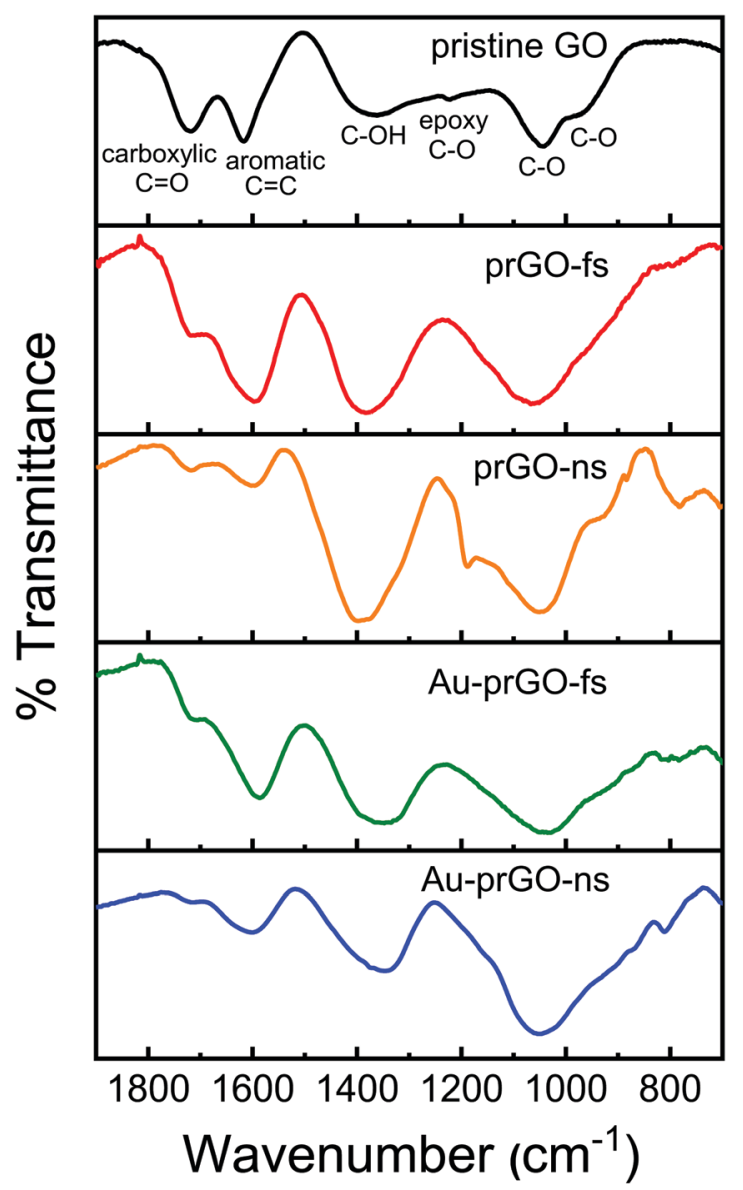

Fig. 3 FTIR spectra of pristine GO (black) and laser processed samples: $\mathrm{GO}$ only with fs (red) and ns (orange), and $\mathrm{GO} /\left[\mathrm{AuCl}_{4}\right]^{-}$with fs (green) and ns (blue) laser. vibrations at $900-1100 \mathrm{~cm}^{-1} \cdot{ }^{44}$ A significant decrease in the intensity of the $\mathrm{C}=\mathrm{O}$ stretch band at $1720 \mathrm{~cm}^{-1}$ were observed for the prGO and $\mathrm{Au}$-prGO samples prepared by both ns and fs laser processing (Fig. 3, red, orange, green, blue). However, no significant decrease is observed in the $\mathrm{C}-\mathrm{OH}$ and $\mathrm{C}-\mathrm{O}$ bands around $1400 \mathrm{~cm}^{-1}$ and $1050 \mathrm{~cm}^{-1}$, respectively. These changes indicate partial reduction of the GO sheets. Interestingly, a small shift to lower energy for the $\mathrm{C}=\mathrm{C}$ stretching vibrations from $\sim 1610 \mathrm{~cm}^{-1}$ to $\sim 1590 \mathrm{~cm}^{-1}$ was observed for the laser-prepared samples, indicating partial restoration of the aromatic structures.

Raman spectroscopy was used to evaluate the degree of graphitization present within prGO prepared without and with $\left[\mathrm{AuCl}_{4}\right]^{-}$by ns and fs laser processing. The Raman spectra (Fig. 4) exhibit a broad $\mathrm{G}$ band at $\sim 1600 \mathrm{~cm}^{-1}$ and $\mathrm{D}$ band at $\sim 1350 \mathrm{~cm}^{-1}$, corresponding to the in-plane vibrational modes of $\mathrm{sp}^{2}$-hybridized carbon atoms and structural disorder at defect sites, respectively. ${ }^{45}$ The intensity ratio of the $\mathrm{D}$ band to that of the $\mathrm{G}$ band can be used to elucidate the degree of graphitization because this ratio approaches zero for highly oriented pyrolytic graphite. ${ }^{44}$ The $I_{\mathrm{D}} / I_{\mathrm{G}}$ ratios determined for the laser-prepared samples ranges from 1.02 to 1.11 , as compared to 1.02 for pristine GO, indicating no significant changes in graphitization due to laser processing.

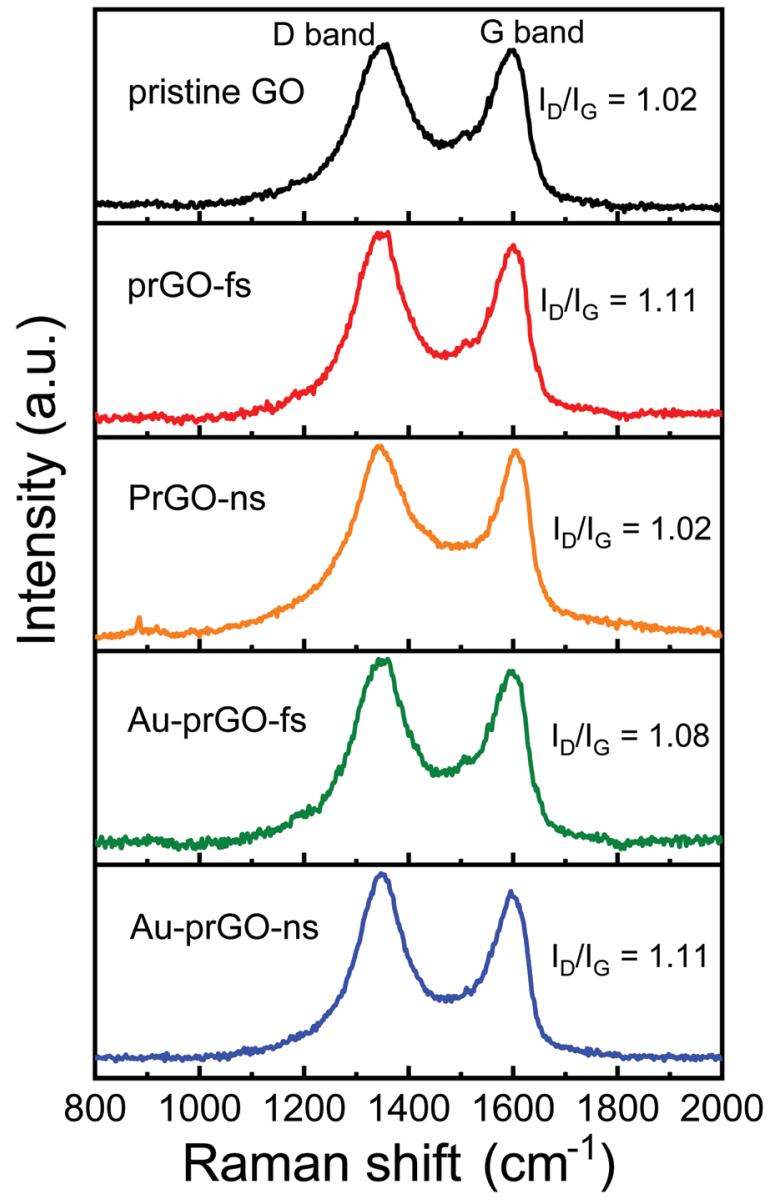

Fig. 4 Raman spectra of pristine GO (black) and laser processed samples: $\mathrm{GO}$ only with fs (red) and ns (orange), and $\mathrm{GO} /\left[\mathrm{AuCl}_{4}\right]^{-}$with fs (green) and ns (blue) laser. 


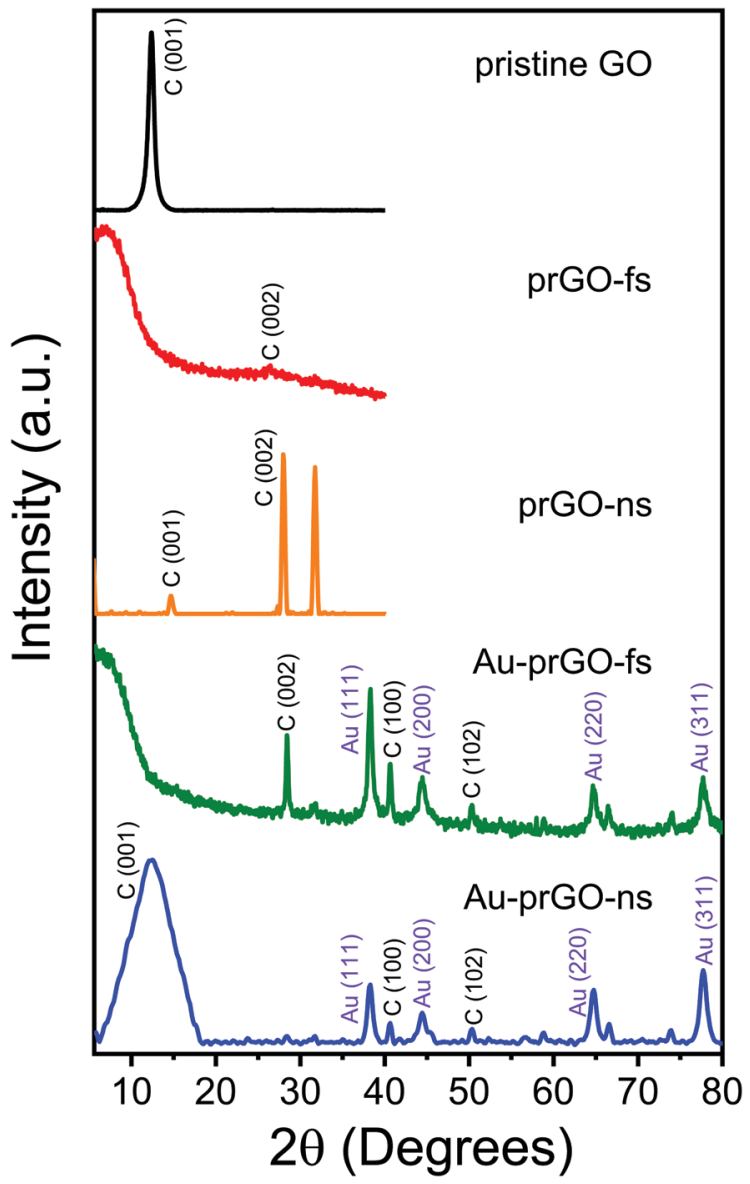

Fig. 5 XRD patterns of pristine GO (black) and laser processed samples: $\mathrm{GO}$ only with fs laser (red) and ns laser (orange), and Au-prGO with fs laser (green) and ns laser (blue).

The XRD pattern of GO (Fig. 5, black) shows a peak at $12.40^{\circ}$, characteristic of (001) GO with an interlayer spacing of $7.15 \AA$, which results from the insertion of hydroxyl and epoxy groups between the graphite sheets during graphite oxidation. ${ }^{36}$ This peak completely disappears for prGO prepared by fs laser processing (Fig. 5, red) and is significantly reduced and shifted to the right by $2^{\circ}$ for prGO prepared by ns laser processing (Fig. 5, orange). The disappearance and shift of the (001) GO peak is attributed to partial reduction of the oxygen-containing functional groups of GO. ${ }^{36,44}$ The small peaks at $26.56^{\circ}$ and $27.89^{\circ}$ for prGO prepared by fs and ns laser processing correspond to graphite (002) with interlayer spacing of $3.37 \AA$ and $3.20 \AA$, respectively. ${ }^{55}$ Both Au-containing samples exhibit additional diffraction planes of graphitic carbon at $40.46^{\circ}$ (100) and $50.37^{\circ}(102) .{ }^{55}$ The Au-prGO sample prepared with ns laser processing (green) exhibits a broad (001) peak at $\sim 12^{\circ}$, corresponding to an interlayer spacing of $7.11 \AA$ and indicating a partial reduction of GO. The complete disappearance of the carbon (001) plane for the fs laser-processed samples could be due to laser-induced fragmentation of the GO. Both Au-containing samples exhibit peaks at $38.32^{\circ}, 44.48^{\circ}, 64.53^{\circ}$, and $77.64^{\circ}$, corresponding to the (111), (200), (220), and (311), planes of fcc Au (JCPDS 01-073-9564).

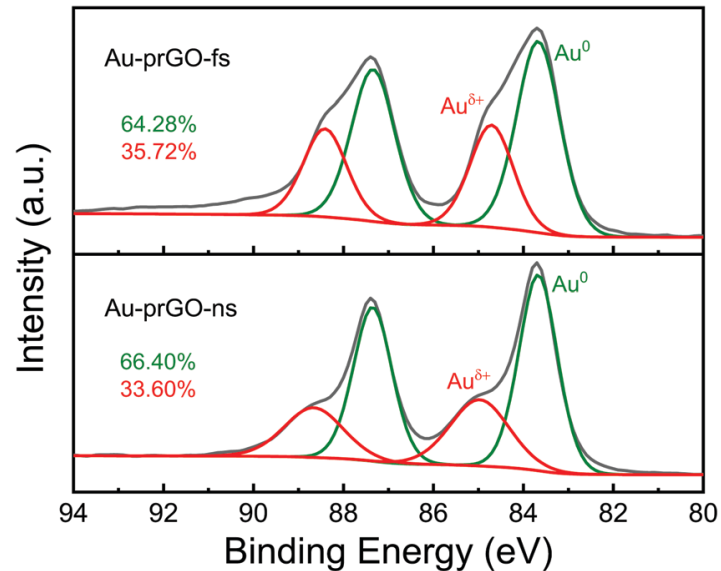

Fig. 6 Au $4 f X P$ spectra for $A u-p r G O$ nanocomposites synthesized with fs (top) and ns (bottom) laser processing. Two peaks corresponding to $\mathrm{Au}^{\circ}$ (green) and $\mathrm{Au}^{\delta+}$ (red) were fit to the data.

Fig. 6 shows the Au $4 \mathrm{f}$ XP spectra for the Au-prGO composites prepared by fs (top) and ns (bottom) laser processing. Both spectra show a Gaussian-Lorentzian deconvoluted peak at centered $83.7 \mathrm{eV}$ for the $\mathrm{Au} 4 \mathrm{f}_{7 / 2}$ species, slightly down-shifted from the typical $\mathrm{Au}^{0}$ value of $84.0 \mathrm{eV}$. This down-shifted value has been observed in some previous reports of Au-GO composites ${ }^{17,19}$ and in our previous reports of Au NPs synthesized by laser processing. ${ }^{47,49,56}$ The down-shift can be attributed to interaction with the GO support, ${ }^{17,19}$ the presence of low-coordinated $\mathrm{Au}$ atoms, ${ }^{47,49,56,57}$ or both. The peaks at $84.7 \mathrm{eV}$ (fs) and $85.0 \mathrm{eV}(\mathrm{ns})$ are slightly lower than the reported for $\mathrm{Au}^{+}(85.6 \mathrm{eV})$ and correspond to partially oxidized $\mathrm{Au}$ atoms, denoted as $\mathrm{Au}^{\delta+}{ }^{58}$ The relative proportions of $\mathrm{Au}^{0}$ and $\mathrm{Au}^{\delta+}$ are similar with both ns and fs laser processing.

Fig. 7 shows the C 1s XP spectra for pristine GO (black) and the laser processed samples of only GO (red and orange) and $\mathrm{GO} /\left[\mathrm{AuCl}_{4}\right]^{-}$(green and blue). Each spectrum was fit to three species assigned to $\mathrm{C}-\mathrm{C}$ at $284.8 \mathrm{eV}, \mathrm{C}-\mathrm{O}$ at $286.8 \mathrm{eV}$, and $\mathrm{C}=\mathrm{O}$

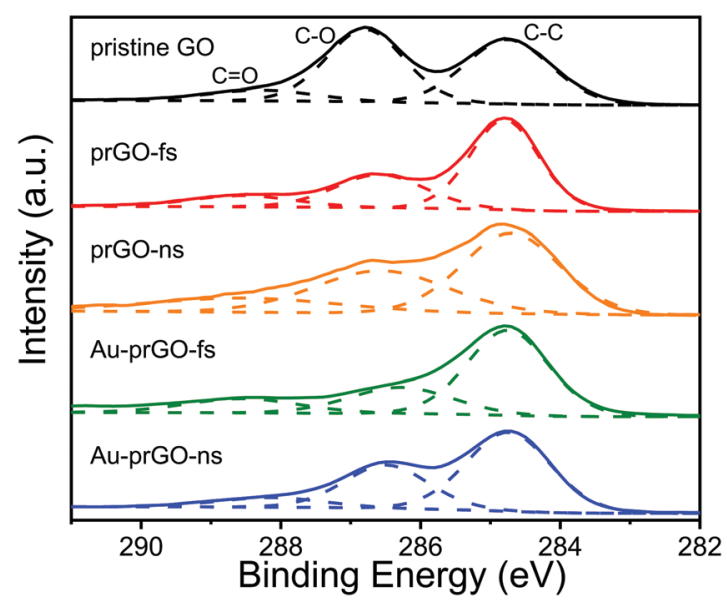

Fig. 7 C1s XP spectra for pristine $\mathrm{GO}$ (black), prGO obtained from fs (red) and ns (orange) processing, and Au-prGO nanocomposites obtained with fs (green) and ns (blue) laser processing. 
Table 1 Relative intensities of fitted C1s peaks and total atomic \% of $\mathrm{C}$ and $\mathrm{O}$ in pristine $\mathrm{GO}$ and laser processed samples

\begin{tabular}{llccc}
\hline sample & $\mathrm{C}-\mathrm{C}$ & $\mathrm{C}-\mathrm{O}$ & $\mathrm{C}=\mathrm{O}$ & $\mathrm{C} / \mathrm{O}$ \\
\hline pristine GO & 44.9 & 45.7 & 9.4 & 0.81 \\
prGO-fs & 59.7 & 29.0 & 11.3 & 1.48 \\
prGO-ns & 48.4 & 34.8 & 16.8 & 0.94 \\
Au-prGO-fs & 61.4 & 24.1 & 14.5 & 1.59 \\
Au-prGO-ns & 58.8 & 32.3 & 8.9 & 1.43
\end{tabular}

at $288.3 \mathrm{eV}$, in accordance with previous reports. ${ }^{17,37,41}$ Processing with both ns and fs lasers resulted in a significant decrease in $\mathrm{C}-\mathrm{O}$ peak intensity relative to pristine GO. While the intensity of the $\mathrm{C}=\mathrm{O}$ component rises in many of the laser processed samples, this likely arises due to uncertainty in peak fitting for a minor component. Table 1 quantifies the relative areas of each fitted species along with the of $\mathrm{C} / \mathrm{O}$ ratio obtained from taking the ratio of the $\mathrm{C}-\mathrm{C}$ to the sum of the $\mathrm{C}-\mathrm{O}$ and $\mathrm{C}=\mathrm{O}$ features. The evident reduction in total oxygenated carbon functional groups is consistent with the changes observed in FTIR and Raman spectroscopy (cf., Fig. 3 and 4). Moreover, the $\mathrm{C} / \mathrm{O}$ ratio is higher for the prGO and $\mathrm{Au}$-prGO samples obtained from fs laser processing as compared to ns laser processing. This greater reduction of GO during fs laser processing is attributed to a longer processing time of $270 \mathrm{~s}$ as compared to the $30 \mathrm{~s}$ with ns pulses used for complete $\left[\mathrm{AuCl}_{4}\right]^{-}$reduction.

\subsection{Catalytic activity of Au-prGO nanocomposites}

PNP reduction by $\mathrm{NaBH}_{4}$ is a widely used benchmark reaction for assessing the catalytic activity of metal NPs. ${ }^{59}$ Fig. 8(a) plots the ratio of the natural $\log$ of the $400 \mathrm{~nm}$ PNP absorbance feature at time $t, A_{t}$, to the initial PNP absorbance, $A_{0}$, as a function of reaction time for $\mathrm{Au}$-prGO nanocomposites produced with ns and fs lasers using $0.0033 \mathrm{mg} \mathrm{mL}^{-1}$ and $0.33 \mathrm{mg} \mathrm{mL}^{-1} \mathrm{GO}$. These reaction kinetics can be used to extract the apparent rate constant $k_{\text {app }},{ }^{60}$ as indicated by the black lines in Fig. 8(a). For both lasers, increasing the GO concentration results in faster PNP conversion. However, the difference in $k_{\text {app }}$ between $\mathrm{Au}$-prGO composites synthesized with fs laser processing at low GO concentrations (red) and high GO concentrations (blue) is significantly greater than for the corresponding $\mathrm{Au}$-prGO composites synthesized with ns laser processing at low (magenta) and high GO concentrations (cyan).

The efficiency of the Au atoms present in the PNP reduction reaction can be quantified by normalizing the $k_{\text {app }}$ value to the moles of $\mathrm{Au}$ added to the reaction. ${ }^{49} 500 \mu \mathrm{L}$ of each $\mathrm{Au}-\mathrm{prGO}$ solution was used in the catalysis reactions, corresponding to $0.05 \mu \mathrm{mol}$ of $\mathrm{Au}$ added. Fig. 8(b) shows the rate constant $\left(k_{\mathrm{Au}}\right)$ normalized to $0.05 \mu \mathrm{mol}$ of $\mathrm{Au}$ obtained for $\mathrm{Au}-$ prGO nanocomposites synthesized by fs (red) and ns (green) lasers at low and high GO concentrations. For reference, the $k_{\mathrm{Au}}$ values obtained from Au NPs synthesized under the same laser conditions with no added GO are shown. When compared to these reference $\mathrm{Au}$ NPs, the addition of low concentrations of GO during irradiation has little effect on $k_{\mathrm{Au}}$ values using both lasers. In contrast, a significant increase in $k_{\mathrm{Au}}$ values is observed
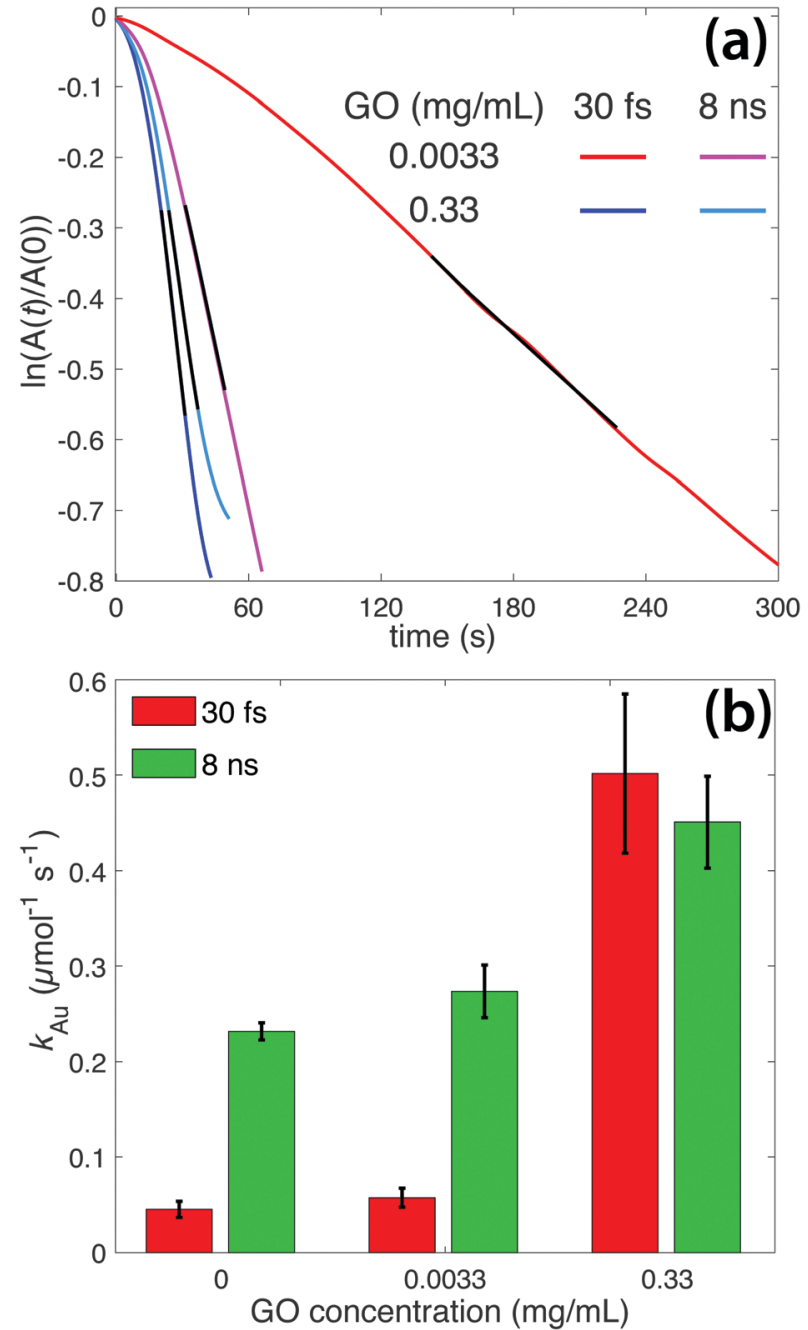

Fig. 8 (a) Absorbance at $400 \mathrm{~nm}$ versus reaction time for PNP reduction using Au-prGO nanocomposites obtained from ns (magenta and cyan) and fs (red and blue) laser processing. Black lines denote the region used to extract $k_{\text {app }}$. (b) Rate constant $k_{\mathrm{Au}}$ for $\mathrm{Au}$-prGO nanocomposites obtained from fs (red) and ns (green) laser processing. Error bars denote standard deviation over at least three independent reactions.

for $\mathrm{Au}$-prGO nanocomposites synthesized with high concentrations of GO for both lasers: The $k_{\mathrm{Au}}$ value roughly doubles for the ns laser product and increases by a factor of 10 for the fs laser product, resulting in similar rates of $k_{\mathrm{Au}}=0.50 \pm 0.08$ and $k_{\mathrm{Au}}=0.45 \pm 0.05 \mu \mathrm{mol}^{-1} \mathrm{~s}^{-1}$ using $0.33 \mathrm{mg} \mathrm{mL}^{-1} \mathrm{GO}$ with fs and ns laser processing, respectively.

The catalytic activity of metal NPs towards PNP reduction is largely dependent on the surface sites available for the reactants to bind. ${ }^{59,60}$ The available surface area, in turn, is inversely proportional to the size of the metal NPs. Hence, the large increase in $k_{\mathrm{Au}}$ for the Au-prGO nanocomposites synthesized with fs laser processing at $0.33 \mathrm{mg} \mathrm{mL}^{-1} \mathrm{GO}$ is expected due to the decreased Au NP sizes obtained with high concentration of GO ( $c f$., Fig. 2). However, decreasing Au NP sizes cannot fully explain the doubling of $k_{\mathrm{Au}}$ in the case of ns laser processing. Even though the proportion of the smallest sub-4 nm Au NPs doubles at $0.33 \mathrm{mg} \mathrm{mL}^{-1} \mathrm{GO}(c f$. , Fig. 2), the average Au NP size 
remains the same. Moreover, the $k_{\mathrm{Au}}=0.23 \pm 0.01 \mu \mathrm{mol}^{-1} \mathrm{~s}^{-1}$ value obtained for the $5 \mathrm{~nm}$ Au NPs synthesized with the ns laser in the absence of GO is nearly identical to the $k_{\mathrm{Au}}=0.22 \pm$ $0.02 \mu \mathrm{mol}^{-1} \mathrm{~s}^{-1}$ obtained for $4 \mathrm{~nm} \mathrm{Au} \mathrm{NPs} \mathrm{synthesized} \mathrm{with}$ tightly focused fs laser pulses in our previous work. ${ }^{49}$ Hence, the presence of GO enhances the PNP reduction rate beyond what would be expected based solely on Au NP size. The observed rate enhancement is likely due to two previously reported synergistic effects between the Au and graphene: (1) the high adsorption of PNP onto graphene and (2) electron donation from graphene to the Au NPs, which facilitates electron transfer to PNP. ${ }^{61}$

\section{Discussion}

Despite extensive investigations into laser synthesis of metalGO nanocomposites, ${ }^{23-42}$ there are no previous reports comparing these materials produced using different laser sources under otherwise similar conditions to the best of our knowledge. Our experiments comparing Au-prGO nanocomposites produced using $532 \mathrm{~nm}, 8 \mathrm{~ns}$ and $800 \mathrm{~nm}, 30$ fs laser sources have identified key differences in the $\left[\mathrm{AuCl}_{4}\right]^{-}$reduction rate and the Au NP size distributions depending on the laser source. Complete conversion of $\left[\mathrm{AuCl}_{4}\right]^{-}$to $\mathrm{Au}$ in the presence of $\mathrm{GO}$ required only $15 \mathrm{~s}$ of processing with ns pulses as compared to $240 \mathrm{~s}$ of processing with fs pulses, and the amount of added GO had a greater effect on $\mathrm{Au}$ NP size distributions for the fs laser source. To understand the origin of these differences, we consider the mechanisms of laser-induced $\left[\mathrm{AuCl}_{4}\right]^{-}$reduction and laser-GO interaction.

In aqueous solution under fs laser excitation, $\left[\mathrm{AuCl}_{4}\right]^{-}$ reduction is driven by the hydrated electrons $\left(\mathrm{e}_{\mathrm{aq}}{ }^{-}\right)$and $\mathrm{H}_{2} \mathrm{O}_{2}$ produced during water photolysis, via the reactions ${ }^{47-49}$

$$
\begin{gathered}
{\left[\mathrm{AuCl}_{4}\right]^{-}+3 \mathrm{e}_{\mathrm{aq}}{ }^{-} \rightarrow \mathrm{Au}^{0}+4 \mathrm{Cl}^{-}} \\
{\left[\mathrm{AuCl}_{4}\right]^{-}+\frac{3}{2} \mathrm{H}_{2} \mathrm{O}_{2}+\mathrm{Au}_{m} \rightarrow \mathrm{Au}_{m+1}+\frac{3}{2} \mathrm{O}_{2}+3 \mathrm{HCl}+\mathrm{Cl}^{-} .}
\end{gathered}
$$

Eqn (1) nucleates $\mathrm{Au}^{0}$ atoms, while eqn (2) results in autocatalytic growth of Au NPs. Under ns laser excitation, we recently proposed a thermally driven mechanism, ${ }^{47}$ initiated by analogous reactions to those proposed for UV excitation ${ }^{62}$

$$
\begin{gathered}
{\left[\mathrm{Au}^{3+} \mathrm{Cl}_{4}\right] \stackrel{\Delta}{\longrightarrow}\left[\mathrm{Au}^{2+} \mathrm{Cl}_{3}\right]^{-}+\mathrm{Cl} .} \\
{\left[\mathrm{Au}^{2+} \mathrm{Cl}_{3}\right]^{-}+\left[\mathrm{Au}^{2+} \mathrm{Cl}_{3}\right] \rightarrow\left[\mathrm{Au}^{3+} \mathrm{Cl}_{4}\right]^{-}+\left[\mathrm{Au}^{+} \mathrm{Cl}_{2}\right]^{-}} \\
3\left[\mathrm{Au}^{+} \mathrm{Cl}_{2}\right] \stackrel{\Delta}{\longrightarrow}\left[\mathrm{Au}^{3+} \mathrm{Cl}_{4}\right]^{-}+2 \mathrm{Au}^{0}+2 \mathrm{Cl}^{-} .
\end{gathered}
$$

Once small quantities of Au NPs are present, resonant excitation of the Au NP SPR with the $532 \mathrm{~nm}$ laser enables rapid autocatalytic reduction of the remaining $\left[\mathrm{AuCl}_{4}\right]^{-} \cdot{ }^{47}$

GO has previously been reported to accelerate metal ion photoreduction through both $532 \mathrm{~nm} \mathrm{~ns} \mathrm{laser}{ }^{35}$ and UV lamp ${ }^{22}$ excitation. This acceleration has been attributed to the one- or two-photon excitation of the GO band gap, ${ }^{2,35,44,45}$ which ranges from approximately $2.5-4 \mathrm{eV}$ for $\mathrm{C} / \mathrm{O}$ ratios of $1-2 .{ }^{63}$ The resulting photoelectrons can reduce oxygen functional groups on $\mathrm{GO},{ }^{44,45}$ along with metal ions, if present. ${ }^{22,35}$ Moreover, the long ns pulse duration as compared to the electron-lattice temperature equilibration timescale of $\sim 1 \mathrm{ps}^{64}$ enables efficient photothermal heating of the GO over the long duration of the laser pulse, further enhancing Au ion reduction. ${ }^{44,45}$

Given these circumstances, the significantly faster $\left[\mathrm{AuCl}_{4}\right]^{-}$ photoreduction in the presence of GO using $532 \mathrm{~nm}, 8 \mathrm{~ns}$ laser pulses is expected for two reasons. First, the nearly sixfold higher linear absorption coefficient of the $0.33 \mathrm{mg} \mathrm{mL}^{-1} \mathrm{GO}$ at $532 \mathrm{~nm}$ of $0.17 \mathrm{OD}$ as compared to the $0.03 \mathrm{OD}$ at $800 \mathrm{~nm}(c f$., Fig. 1, black curves) results in the GO more efficiently absorbing the $532 \mathrm{~nm}$ light. The $532 \mathrm{~nm}$ wavelength $(2.33 \mathrm{eV})$ can also access the GO band gap with absorption of two photons, while the $800 \mathrm{~nm}$ wavelength of the fs laser $(1.55 \mathrm{eV})$ requires absorption of three photons. Despite the higher peak intensity of the fs laser, the more efficient linear and two-photon absorption at $532 \mathrm{~nm}$ is expected to result in the GO interacting much more strongly with the $532 \mathrm{~nm}$ laser. Second, the short duration of the fs laser pulse ( $30 \mathrm{fs}$ ) compared to electronlattice temperature equilibration time ( $1 \mathrm{ps})$ is expected to limit the efficient transfer of the laser energy into heat because the laser pulse is no longer present once the GO has reached thermal equilibrium, so no photothermal enhancement can occur. Hence, both excitation efficiency and photothermal effects likely contribute to the faster $\left[\mathrm{AuCl}_{4}\right]^{-}$reduction in the presence of GO observed using $532 \mathrm{~nm}$ ns laser excitation.

The weaker effect of $\mathrm{GO}$ on $\left[\mathrm{AuCl}_{4}\right]^{-}$reduction using $800 \mathrm{~nm}$ fs laser pulses as compared to $532 \mathrm{~nm}$ ns pulses can account for the different Au NP size distributions ( $c f$., Fig. 2). The consistent production of $\sim 5 \mathrm{~nm}$ Au NPs at any GO concentration with ns laser processing likely results from the $532 \mathrm{~nm}$ wavelength being resonant with the Au NP SPR feature, resulting in efficient fragmentation of any Au NPs that grow larger than $\sim 10 \mathrm{~nm} .{ }^{47}$ In contrast, increasing concentration of GO results in a modest decrease in the mean diameter of the large Au NPs from 18 to $10 \mathrm{~nm}$ using fs laser processing. To further explore the origins of this size reduction, additional experiments using GO concentrations between 0.0033 and $0.33 \mathrm{mg} \mathrm{mL}^{-1}$ with fs laser processing were performed. Fig. 9(a) displays the SPR absorbance as a function of fs laser processing time for different GO concentrations. The addition of increasing amounts of GO results in gradually faster $\left[\mathrm{AuCl}_{4}\right]^{-}$reduction kinetics. The reduction kinetics for low GO concentrations display the typical ' $\mathrm{S}$ ' shape indicating operation of the two-step Finke-Watsky autocatalytic rate law, ${ }^{65}$ which has been established for $\left[\mathrm{AuCl}_{4}\right]^{-}$photoreduction via water photolysis. ${ }^{47-49}$ However, high GO concentrations result in the SPR growth kinetics becoming nearly linear, indicating the emergence of a first-order rate law. This gradual shift with increasing GO concentration from autocatalytic to firstorder kinetics suggests a transition from reduction by water photolysis to GO-mediated reduction.

The effect of increasing GO concentration on both $\left[\mathrm{AuCl}_{4}\right]^{-}$ reduction rate and $\mathrm{Au}$ NP size can be clearly seen in Fig. 9(b), which plots the required completion times (blue squares) along with the $\mathrm{Au}$ NP size distributions obtained from TEM analysis (red triangles and magenta diamonds) as a function of GO concentration. Compared to the reaction with no added GO, increasing the GO concentration results in a gradual decrease 

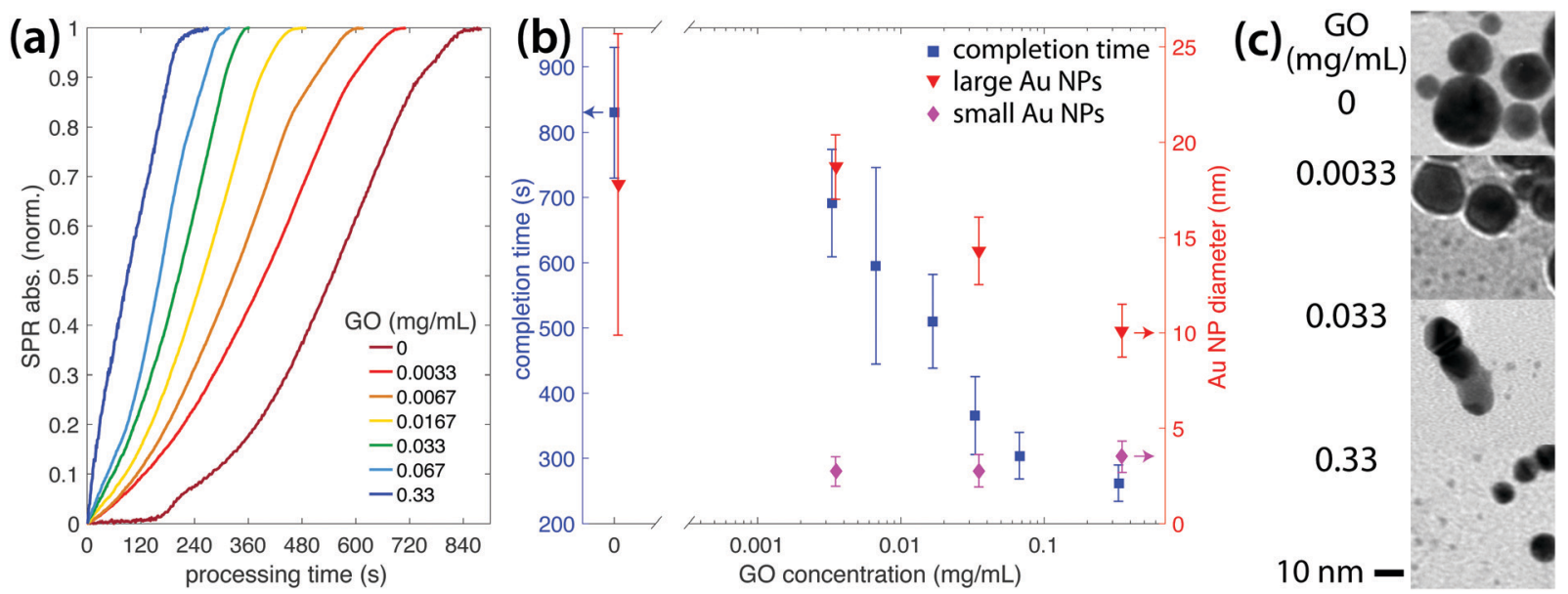

Fig. 9 (a) Fractional growth of the Au SPR absorbance feature versus fs laser processing time for various GO concentrations. (b) Completion time (blue) and Au NP sizes (red and magenta) at different GO concentrations. (c) Representative TEM images at different GO concentrations.

in the required processing time until saturation at concentrations above $0.067 \mathrm{mg} \mathrm{mL}^{-1}$. A concomitant decrease in the size of the large Au NPs from 18 to $10 \mathrm{~nm}$ is observed. Interestingly, the addition of even a small amount $\left(0.0033 \mathrm{mg} \mathrm{mL}^{-1}\right)$ of $\mathrm{GO}$ focuses the size distribution of the large Au NPs, as the standard deviation of the size distributions for GO containing samples was less than $2 \mathrm{~nm}$. The small $\sim 2-3 \mathrm{~nm}$ Au NPs are observed at all GO concentrations (Fig. 9(c)), and fewer large Au NPs relative to the small ones are observed with increasing GO concentration (ESI, $\dagger$ Fig. S2). This increasing production of ultrasmall Au clusters with GO concentration suggests that they are formed by the GO-mediated reduction pathway. The large $\mathrm{Au}$ NPs likely arise from the remaining $\left[\mathrm{AuCl}_{4}\right]^{-}$being reduced through the typical water photolysis pathways discussed previously. ${ }^{47-49}$ However, the decreasing size of these NPs as GO concentration increases suggests that the presence of GO slows Au NP growth. To uncover the origin of this GO activity, we quantified the $\mathrm{H}_{2} \mathrm{O}_{2}$ produced during fs laser processing of water and $0.33 \mathrm{mg} \mathrm{mL}^{-1} \mathrm{GO}$ solution because $\mathrm{H}_{2} \mathrm{O}_{2}$ is known to induce autocatalytic Au NP growth. ${ }^{47-50}$ As compared to pure water, laser processing of $0.33 \mathrm{mg} \mathrm{mL}^{-1} \mathrm{GO}$ solution produced $\sim 50 \%$ less $\mathrm{H}_{2} \mathrm{O}_{2}$ for the same processing time (ESI, $\dagger$ Fig. S3). Hence, the slowing of Au NP growth in the presence of GO can be attributed to the radical-scavenging behavior of GO that limits the production of $\mathrm{H}_{2} \mathrm{O}_{2}$.

The operation of parallel $\left[\mathrm{AuCl}_{4}\right]^{-}$reduction mechanisms by water photolysis and GO in the case of fs laser processing accounts for the two distinct populations of large and small $\mathrm{Au}$ NPs. Even at the highest GO concentrations investigated, the GO-mediated reduction is not sufficiently rapid to completely eliminate the water photolysis pathway. Nevertheless, the radical-scavenging behavior of $\mathrm{GO}$ evident in the reduced $\mathrm{H}_{2} \mathrm{O}_{2}$ production provides the potential to exert control over the size distributions of the large Au NPs comprising the majority of Au mass by manipulating the $\left[\mathrm{AuCl}_{4}\right]^{-} / \mathrm{GO}$ ratio in the precursor solution. Hence, fs laser processing may be more desirable for applications requiring large, monodisperse $\mathrm{Au}$ NPs such as sensing. In contrast, the extremely rapid $\left[\mathrm{AuCl}_{4}\right]^{-}$ reduction using ns laser processing attributed to the more efficient activation of GO-mediated reduction pathways results in a single, albeit broader, Au NP size distribution. As a result, ns laser processing is expected to produce similar Au NP size distributions regardless of the $\left[\mathrm{AuCl}_{4}\right]^{-} / \mathrm{GO}$ ratio in the precursor solution. Moreover, the use of the resonant $532 \mathrm{~nm}$ laser wavelength ensures that the Au NP size distributions will be centered at $\sim 5 \mathrm{~nm}$, thereby imparting high catalytic activity.

\section{Conclusion}

This work presented the first direct comparison of Au-prGO nanocomposites produced by photoreduction of $\left[\mathrm{AuCl}_{4}\right]^{-}$in the presence of GO using ns and fs laser processing. In contrast to previous works using $\mathrm{ns}^{35-38}$ and $\mathrm{fs}^{39-42}$ laser processing to produce metal-GO nanocomposites via metal ion photoreduction, this work directly compared the products produced using two different laser sources and investigated the effect of GO concentration. For ns laser processing, the similar Au NP size distributions centered around $\sim 5 \mathrm{~nm}$ regardless of GO concentration were attributed to the rapid GO-mediated photothermal reduction of $\left[\mathrm{AuCl}_{4}\right]^{-}$. In contrast, the slower $\left[\mathrm{AuCl}_{4}\right]^{-}$ reduction and production of two distinct Au NP size distributions using fs laser processing was attributed to the operation of both GO- and water photolysis-mediated $\left[\mathrm{AuCl}_{4}\right]^{-}$reduction. Moreover, the size reductions of the large Au NPs with increasing GO concentration using fs laser processing induced by the radicalscavenging behavior of GO provides a means of manipulating $\mathrm{Au}$ NP size distributions. Overall, the results of this work indicate that both ns and fs laser processing are suitable for producing active $\mathrm{Au}$-prGO nanocatalysts with small Au NP sizes, while fs laser processing may be preferable for applications that require large and monodisperse Au NPs.

\section{Conflicts of interest}

There are no conflicts to declare. 


\section{Acknowledgements}

This work was supported by the National Science Foundation (CHE-1900094) (MSE) and the American Chemical Society Petroleum Research Fund (57799-DNI10) (KMT). Microscopy was performed at the VCU Department of Anatomy and Neurobiology Microscopy Facility, supported by the Higher Education Equipment Trust Fund Grant No. 236160307.

\section{Notes and references}

1 S. Bai and X. Shen, RSC Adv., 2012, 2, 64-98.

2 M. Khan, M. N. Tahir, S. F. Adil, H. U. Khan, M. R. H. Siddiqui, A. A. Al-warthan and W. Tremel, J. Mater. Chem. A, 2015, 3, 18753-18808.

3 P. T. Yin, S. Shah, M. Chhowalla and K.-B. Lee, Chem. Rev., 2015, 115, 2483-2531.

4 K. Turcheniuk, R. Boukherroub and S. Szunerits, J. Mater. Chem. B, 2015, 3, 4301-4324.

5 Y.-W. Chen, Y.-L. Su, S.-H. Hu and S.-Y. Chen, Adv. Drug Delivery Rev., 2016, 105, 190-204.

6 S. Navalon, A. Dhakshinamoorthy, M. Alvaro and H. Garcia, Coord. Chem. Rev., 2016, 312, 99-148.

7 M. N. I. Amir, A. Halilu, N. M. Julkapli and A. Ma'amor, J. Ind. Eng. Chem., 2020, 83, 1-13.

8 X. Li, J. Zhu and B. Wei, Chem. Soc. Rev., 2016, 45, 3145-3187. 9 T. Demeritte, B. P. Viraka Nellore, R. Kanchanapally, S. S. Sinha, A. Pramanik, S. R. Chavva and P. C. Ray, ACS Appl. Mater. Interfaces, 2015, 7, 13693-13700.

10 P. G. Vianna, D. Grasseschi, G. K. B. Costa, I. C. S. Carvalho, S. H. Domingues, J. Fontana and C. J. S. de Matos, ACS Photonics, 2016, 3, 1027-1035.

11 S. Kang, J. Lee, S. Ryu, Y. Kwon, K.-H. Kim, D. H. Jeong, S. R. Paik and B.-S. Kim, Chem. Mater., 2017, 29, 3461-3476.

12 X. Zhou, Z. Zhang, X. Lu, X. Lv, G. Ma, Q. Wang and Z. Lei, ACS Appl. Mater. Interfaces, 2017, 9, 34927-34936.

13 M. L. d. O. Pereira, D. Grasseschi and H. E. Toma, Energy Fuels, 2018, 32, 2673-2680.

14 Q. Tan, X. Kong, X. Guan, C. Wang and B. Xu, CrystEngComm, 2020, 22, 320-329.

15 Y. Wei, X. Zuo, X. Li, S. Song, L. Chen, J. Shen, Y. Meng, Y. Zhao and S. Fang, Mater. Res. Bull., 2014, 53, 145-150.

16 D. Sun, M. Tang, L. Zhang, B. G. Falzon, D. B. Padmanaban, D. Mariotti, P. Maguire, H. Xu, M. Chen and D. Sun, Nanotechnology, 2019, 30, 455603.

17 K. Hareesh, R. Joshi, D. V. Sunitha, V. Bhoraskar and S. Dhole, Appl. Surf. Sci., 2016, 389, 1050-1055.

18 Y. Yue, B. Zhou, J. Shi, C. Chen, N. Li, Z. Xu, L. Liu, L. Kuang, M. Ma and H. Fu, Appl. Surf. Sci., 2017, 403, 282-293.

19 P. Wang, Z.-G. Liu, X. Chen, F.-L. Meng, J.-H. Liu and X.-J. Huang, J. Mater. Chem. A, 2013, 1, 9189-9195.

20 R. Martnez-Orozco, H. Rosu, S.-W. Lee and V. RodrguezGonzález, J. Hazard. Mater., 2013, 263, 52-60.

21 Y. Qin, J. Li, Y. Kong, X. Li and H. Xue, J. Electrochem. Soc., 2014, 161, H172-H177.
22 H. S. Rady, A. N. Emam, M. B. Mohamed and M. S. El-Shall, Chem. Phys. Lett., 2017, 690, 153-158.

23 Y. Yang, M. Shi, Q.-F. Zhou, Y.-S. Li and Z.-W. Fu, Electrochem. Commun., 2012, 20, 11-14.

24 J. Li, Q. Han, X. Wang, N. Yu, L. Yang, R. Yang and C. Wang, Small, 2014, 10, 4386-4394.

25 A. R. Sadrolhosseini, A. Noor, N. Faraji, A. Kharazmi and M. Mahdi, J. Nanomater., 2014, 2014, 962917.

26 R. S. Siddhardha, V. L. Kumar, A. Kaniyoor, V. S. Muthukumar, S. Ramaprabhu, R. Podila, A. Rao and S. S. Ramamurthy, Spectrochim. Acta, Part A, 2014, 133, 365-371.

27 V. L. Kumar, R. S. S. Siddhardha, A. Kaniyoor, R. Podila, M. Molli, S. M. Kumar, K. Venkataramaniah, S. Ramaprabhu, A. M. Rao and S. S. Ramamurthy, Electroanalysis, 2014, 26, 1850-1857.

28 R. Torres-Mendieta, D. Ventura-Espinosa, S. Sabater, J. Lancis, G. Mnguez-Vega and J. A. Mata, Sci. Rep., 2016, 6, 30478.

29 H. He, H. Wang, K. Li, J. Zhu, J. Liu, X. Meng, X. Shen, X. Zeng and W. Cai, Langmuir, 2016, 32, 1667-1673.

30 P. Wang, Y. Ye, D. Liang, H. Sun, J. Liu, Z. Tian and C. Liang, RSC Adv., 2016, 6, 26977-26983.

31 R. A. Moqbel, M. A. Gondal, T. F. Qahtan and M. A. Dastageer, Int. J. Energy Res., 2018, 42, 1487-1495.

32 I. Haxhiaj, S. Tigges, D. Firla, X. Zhang, U. Hagemann, T. Kondo, J. Nakamura, G. Marzun and S. Barcikowski, Appl. Surf. Sci., 2019, 469, 811-820.

33 S. Hu, E. L. Ribeiro, S. A. Davari, M. Tian, D. Mukherjee and B. Khomami, RSC Adv., 2017, 7, 33166-33176.

34 X. Kang, D. Teng, S. Wu, Z. Tian, J. Liu, P. Li, Y. Ma and C. Liang, J. Colloid Interface Sci., 2020, 566, 265-270.

35 S. Moussa, G. Atkinson, M. El-Shall, A. Shehata, K. M. AbouZeid and M. B. Mohamed, J. Mater. Chem., 2011, 21, 9608-9619.

36 S. Moussa, V. Abdelsayed and M. S. El-Shall, Chem. Phys. Lett., 2011, 510, 179-184.

37 S. Moussa, A. R. Siamaki, B. F. Gupton and M. S. El-Shall, ACS Catal., 2012, 2, 145-154.

38 M. Sygletou, P. Tzourmpakis, C. Petridis, D. Konios, C. Fotakis, E. Kymakis and E. Stratakis, J. Mater. Chem. A, 2016, 4, 1020-1027.

39 D. Tan, X. Liu, Y. Dai, G. Ma, M. Meunier and J. Qiu, Adv. Opt. Mater., 2015, 3, 836-841.

40 Y. Yu, L. Yan, M. Yue and H. Xu, R. Soc. Open Sci., 2018, 5, 171436.

41 M. Yue, J. Si, L. Yan, Y. Yu and X. Hou, Opt. Mater. Express, 2018, 8, 698-703.

42 Y. Yu, L. Yan, J. Si, Y. Xu and X. Hou, J. Phys. Chem. Solids, 2019, 132, 116-120.

43 W. S. Hummers and R. E. Offeman, J. Am. Chem. Soc., 1958, 80, 1339.

44 V. Abdelsayed, S. Moussa, H. M. Hassan, H. S. Aluri, M. M. Collinson and M. S. El-Shall, J. Phys. Chem. Lett., 2010, 1, 2804-2809.

45 D. A. Sokolov, K. R. Shepperd and T. M. Orlando, J. Phys. Chem. Lett., 2010, 1, 2633-2636.

46 D. Amans, W. Cai and S. Barcikowski, Appl. Surf. Sci., 2019, 488, 445-454. 
47 C. J. Rodrigues, J. A. Bobb, M. G. John, S. P. Fisenko, M. S. El-Shall and K. M. Tibbetts, Phys. Chem. Chem. Phys., 2018, 20, 28465-28475.

48 V. K. Meader, M. G. John, C. J. Rodrigues and K. M. Tibbetts, J. Phys. Chem. A, 2017, 121, 6742-6754.

49 L. M. Frias Batista, V. K. Meader, K. Romero, K. Kunzler, F. Kabir, A. Bullock and K. M. Tibbetts, J. Phys. Chem. B, 2019, 123, 7204-7213.

50 V. K. Meader, M. G. John, L. M. Frias Batista, S. Ahsan and K. M. Tibbetts, Molecules, 2018, 23, 532.

51 G. Eisenberg, Ind. Eng. Chem., Anal. Ed., 1943, 15, 327-328.

52 Y. R. Shen, The Principles of Nonlinear Optics, Wiley, New York, 1984.

53 V. Kandidov, O. Kosareva, I. Golubtsov, W. Liu, A. Becker, N. Akozbek, C. Bowden and S. Chin, Appl. Phys. B: Lasers Opt., 2003, 77, 149-165.

54 A. Vogel, J. Noack, G. Hüttman and G. Paltauf, Appl. Phys. B: Lasers Opt., 2005, 81, 1015-1047.

55 Z. Li, C. Lu, Z. Xia, Y. Zhou and Z. Luo, Carbon, 2007, 45, 1686-1695.
56 M. G. John and K. M. Tibbetts, Appl. Surf. Sci., 2019, 475, 1048-1057.

57 A. Y. Klyushin, T. C. R. Rocha, M. Hävecker, A. Knop-Gericke and R. Schlögl, Phys. Chem. Chem. Phys., 2014, 16, 7881-7886.

58 M. P. Casaletto, A. Longo, A. Martorana, A. Prestianni and A. M. Venezia, Surf. Interface Anal., 2006, 38, 215-218.

59 T. Aditya, A. Pal and T. Pal, Chem. Commun., 2015, 51, 9410-9431.

60 S. Wunder, F. Polzer, Y. Lu, Y. Mei and M. Ballauff, J. Phys. Chem. C, 2010, 114, 8814-8820.

61 J. Li, C.-y. Liu and Y. Liu, J. Mater. Chem., 2012, 22, 8426-8430.

62 S. Eustis, H.-Y. Hsu and M. A. El-Sayed, J. Phys. Chem. B, 2005, 109, 4811-4815.

63 J.-A. Yan, L. Xian and M. Y. Chou, Phys. Rev. Lett., 2009, 103, 086802.

64 F. Carbone, P. Baum, P. Rudolf and A. H. Zewail, Phys. Rev. Lett., 2008, 100, 035501.

65 M. A. Watzky and R. G. Finke, J. Am. Chem. Soc., 1997, 119, 10382-10400. 